\title{
Concordance of patient beliefs and expectations regarding the management of low back pain with guideline recommendations - a cross-sectional study in Germany
}

\author{
Simone Kiel ${ }^{* *}$ (D), Christina Raus ${ }^{1}$, Elizabeth Sierocinski ${ }^{1}$ (D), Peggy Knauthe ${ }^{2}$ and Jean-François Chenot ${ }^{1}$ (D)
}

\begin{abstract}
Background: Low back pain is a common reason for patients to seek medical care. Physician non-adherence to clinical guidelines has been observed. We investigated the extent to which patient expectations correspond to recommendations of the German national guideline for management of low back pain (G-LBP) and whether patient characteristics, history of LBP and previous treatment experience are associated with expectations.

Methods: A cross-sectional study including patients from 13 general practices was conducted. Data were collected using a questionnaire. Inverse probability weights were used to address non-response bias. Descriptive analysis and multivariate logistic regression models were performed.

Results: A total of 977 patients were included in analyses (median age 57 years, 39\% male). 75\% of patients reported experiencing LBP currently or within the last year. More than $65 \%$ indicated they would agree to forgo further examinations if their LBP was judged by their physician to be of no serious concern. This was associated with the highest level of education and no prior imaging, and negatively associated with good-to-poor health status and moderate-to-severe pain intensity. 40\% of participants expected imaging. The highest educational level, female gender and no prior imaging were associated with a decreased expectation of imaging. $70 \%$ expected prescriptions for massages. Females, participants with good-to-poor health status, current LBP or LBP in the last 12 months had an increased expectation for massages. Expectations for injection therapy (45\%) were mainly associated with previous injections. Expectations for physiotherapy (64\%) were associated with female gender, lower educational level, good-to-poor health status, current LBP or in the last 12 months. The perspective that daily activities should be continued (66\%) was associated with female gender and higher educational level. Participants who agreed to the statement 'There is no effective treatment for LBP' (11\%) had a poor health status, current LBP and a severe pain intensity.

(Continued on next page)
\end{abstract}

*Correspondence: simone.kiel@uni-greifswald.de

'Department of General Practice, Institute of Community Medicine, University Medicine Greifswald, Fleischmannstraße 6, 17475 Greifswald, Germany

Full list of author information is available at the end of the article

C C The Author(s). 2020 Open Access This article is licensed under a Creative Commons Attribution 4.0 International License, which permits use, sharing, adaptation, distribution and reproduction in any medium or format, as long as you give appropriate credit to the original author(s) and the source, provide a link to the Creative Commons licence, and indicate if changes were made. The images or other third party material in this article are included in the article's Creative Commons licence, unless indicated otherwise in a credit line to the material. If material is not included in the article's Creative Commons licence and your intended use is not permitted by statutory regulation or exceeds the permitted use, you will need to obtain permission directly from the copyright holder. To view a copy of this licence, visit http://creativecommons.org/licenses/by/4.0/. The Creative Commons Public Domain Dedication waiver (http://creativecommons.org/publicdomain/zero/1.0/) applies to the data made available in this article, unless otherwise stated in a credit line to the data. 
(Continued from previous page)

Conclusion: Patient views regarding LBP management are partially concordant with guideline recommendations and are strongly influenced by previous treatment experiences and education level. Exploration of patient expectations and experiences in LBP treatment may help minimize dissatisfaction of patients expecting treatments not endorsed by guidelines and simultaneously increase physician guideline adherence.

Keywords: Clinical guidelines, Low back pain, Patient expectations, Patient preferences, Non-adherence

\section{Background}

Low back pain (LBP) is the global leading cause of years lived with disability (YLDs) [1]. A 17\% increase of YLDs attributable to LBP was observed worldwide from 2007 to 2017 [1]. In Germany, 15-20\% of the population suffers from chronic LBP [2] and 25\% of all adults with statutory health insurance consult a physician for LBP at least once a year [3]. The German national guideline for management of LBP (G-LBP) (updated in 2017 and in line with international guidelines) recommends to refrain from advanced diagnostics such as imaging and laboratory examinations if clinical examination indicates non-specific LBP and to encourage physical activity [4, 5]. Non-specific LBP is defined as the absence of a specific pathology, such as tumour, infection or fracture [6]. LBP related to serious diseases is rare in primary care [4-6].

Variations in diagnostic procedures and treatment of LBP as well as non-adherence to guidelines have been observed in general practice [7-10]. There is evidence that the impact of clinical guidelines for LBP management on clinical practice is minimal [11-13]. Reasons for nonadherence to guidelines by clinicians include lack of awareness of new guidelines, insufficient time and resources to offer recommended care [11, 14, 15]. Additionally, patient preferences and expectations for the management of LBP strongly influence physician adherence to guideline-based recommendations [16]. For example, general practitioners (GPs) may fear that patients will consult another general practice if their expectations are not met [15]. Also, a qualitative study found that GPs were concerned that postponing diagnostic and therapeutic interventions in LBP would cause patients to feel that their pain was not being taken seriously and that their condition was being downplayed [15]. However, fulfilling patient treatment preferences is only inconsistently associated with successful treatment outcomes [17-19]. Patient beliefs, expectations and preferences must be taken into account in order to prevent non-adherence to treatment plans as well as unnecessary use of healthcare resources such as imaging [20-22]. Based on this information, it is possible that the implementation of the G-LBP is influenced by patient expectations and beliefs.

The aim of this study was to investigate the extent to which patient expectations regarding imaging, massages, injection therapy, physiotherapy and maintaining daily activity coincide with the recommendations of the German national disease management guideline for LBP (GLBP). The secondary aim was to investigate the associations between patient characteristics, patient history of LBP, and previous treatment experiences with beliefs and expectations regarding the management of LBP.

\section{Methods}

\section{Study design and setting}

This cross-sectional study was carried out from June to September 2018 in 13 general practices in MecklenburgVorpommern, Germany. For 3 days, the nurses employed in the practices approached all patients entering the practice, regardless of reason for consultation. This was done to assess whether expectations regarding LBP management differ between individuals with and without current LBP. Practice nurses approached patients consecutively and provided written information. After providing informed consent, patients received a questionnaire to fill out prior to their consultation with the GP. The anonymous questionnaires were placed in a secure container to ensure data privacy. The practice nurse kept a list of all patients with an anonymous, consecutive number, year of birth, gender, participation / non-participation and reason of non-participation (where applicable).

\section{Exclusion criteria}

Patients who were not able to give written informed consent and/or patients under the age of 18 and/or patients with insufficient German language skills were not eligible for the study (Fig. 1, Reasons for non-approach). Eight patients $<18$ years were mistakenly approached by the practice nurses. Those eight patients were excluded from the sample because they did not meet the inclusion criteria.

\section{Questionnaire}

The questionnaire was developed based on core recommendations of the German LBP guideline (G-LBP) [23] and the Back Beliefs Questionnaire from Jenkins et al. [24]. Demographic data, current health status and history of LBP were assessed. Patients who reported LBP during the last 12 months were prompted to answer 7 


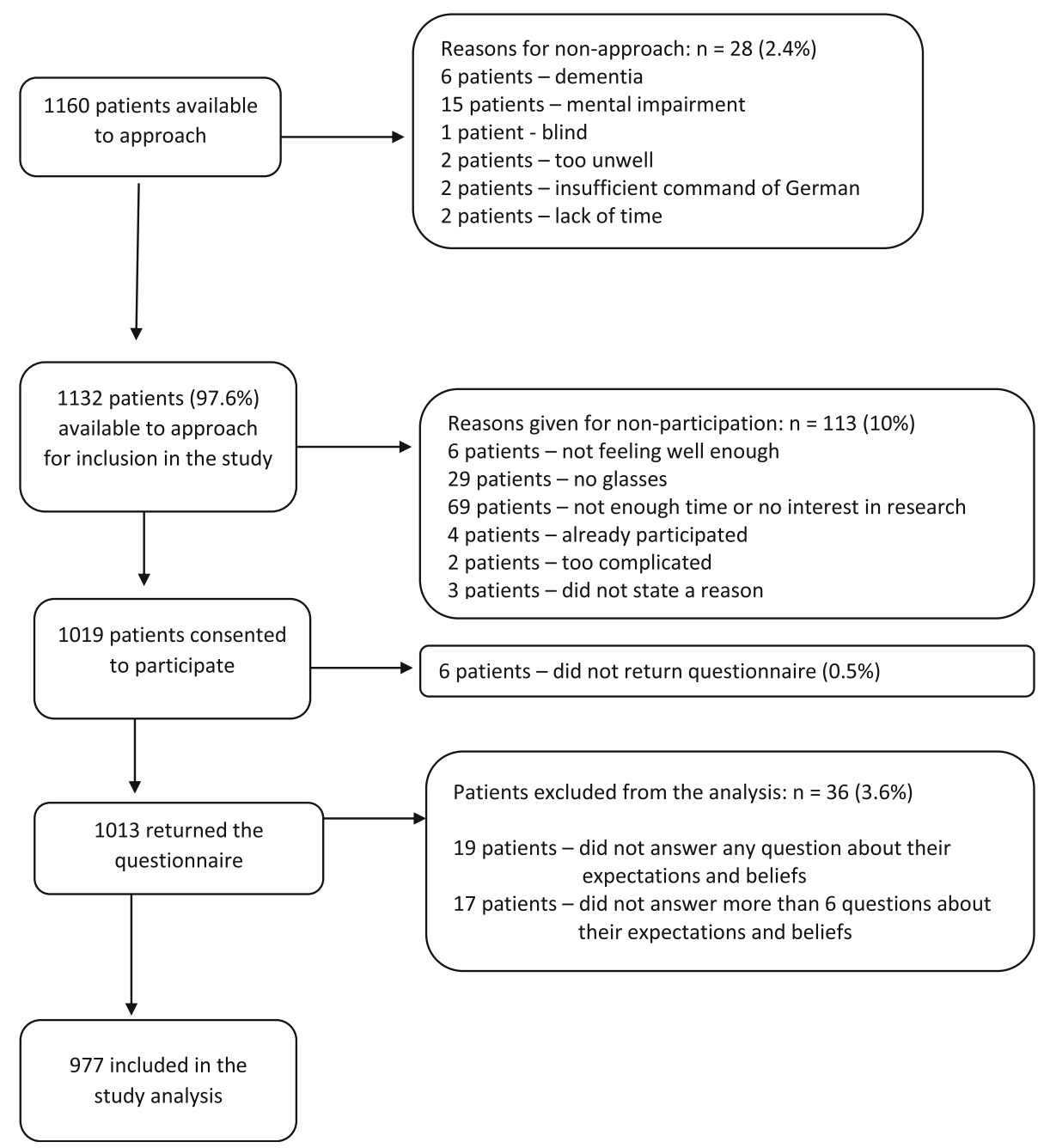

Fig. 1 Flow chart of participant recruitment

additional questions about pain intensity, impairment of daily activity, and any imaging for LBP during the last 12 months (items 6-12, Additional file 1). Patients who denied having back pain in the last 12 months skipped these questions. Agreement with statements extracted from the core recommendations of the G-LBP regarding diagnosis and treatment of LBP, specifically imaging, massages, injections, physiotherapy, and maintaining daily activity, were measured on a 4-point Likert scale ranging from strongly agree to strongly disagree. A neutral midpoint was not included, but participants had the option to answer "Don't know". Validated questionnaires regarding patient expectations, beliefs and their concordance with recommendations of the national guideline for management of LBP are not available. Instead, the questionnaire was first piloted with 12 patients who volunteered reading the statements aloud and explaining their understanding. Additionally, we piloted the questionnaire in three practices with 139 patients. Based on the feedback, we rephrased several questions, reduced the number and changed the order of the questions. An English translation of the questionnaire is provided in the Additional file 1.

\section{Data analyses \\ Bias}

Out of 1160 consulting patients, 1013 agreed to participate and submitted their responses to the questionnaire (response rate: 87\%) (Fig. 1). The Mann-Whitney-U-Test was used to determine age differences and the chisquare test to determine gender differences between participants and non-participants. We found that nonparticipants $(n=147)$ were older $(p<0.0001)$ and more frequently males $(p=0.001)$ (Table 1$)$. To address this nonresponse bias, inverse probability weights (ipw) were calculated. To calculate ipw, a logistic regression was performed using study participation (yes/no) as the outcome, and age and gender as predictors. The reciprocal 
Table 1 Baseline characteristics of participants and non-participants

\begin{tabular}{llll}
\hline & $\begin{array}{l}\text { Participants } \\
\boldsymbol{n}=\mathbf{1 0 1 3}\end{array}$ & $\begin{array}{l}\text { Non-participants } \\
\boldsymbol{n}=\mathbf{1 4 7}\end{array}$ & $\boldsymbol{p}$-value \\
\hline $\begin{array}{l}\text { Median age in years }\left(\mathrm{Q}_{1} ; \mathrm{Q}_{3}\right) \\
\text { Gender }\end{array}$ & $57^{\mathrm{a}}(41 ; 68)$ & $66(52 ; 80)$ & $<0.0001$ \\
& & $79(53.7 \%)^{c}$ & 0.001 \\
\hline Men, $n(\%)$ & $402(39,7 \%)^{\mathrm{b}}$ &
\end{tabular}

of participation probability was considered in the analysis.

\section{Outcomes and predictor variables}

Outcome variables were the response categories, dichotomized in agreement (strongly agree and agree) and disagreement (strongly disagree and disagree). Participants who answered 'Don't know' were excluded from the particular regression model. The predictor age was kept as a continuous variable. Educational level was grouped into $<10$ years (lower secondary school, other, and no school graduation), 10 years (secondary school, polytechnical institute) and $>10$ years (high school, advanced college entrance qualification) of education. Self-assessed health status was grouped in excellent or very good, good, fair, or poor. The predictor 'low back pain on a 10 -point scale' was grouped into mild ( $0-5$ points), moderate (6-7 points) and severe (8-10 points), corresponding to a study from Boonstra et al. [25]. Prior imaging for LBP (Yes/No) and analgesics for LBP (Yes/No) referred to the last 12 months. Prior injection therapy (Yes/No) referred to 'ever' having injection therapy for LBP.

\section{Statistical methods}

Participants who did not answer more than six questions about their beliefs and expectations $(n=36)$ were excluded from the analysis. Data analysis was of descriptive-explorative nature. Descriptive statistics were used to assess response frequency. Multivariate logistic regression analysis was used to assess the association between the predictor variables age, gender, educational level, self-assessed health status, current LBP or history of LBP, prior injection therapy, LBP on a 10-point scale during the last year and prior imaging for LBP. An additional analysis was carried out including only the subgroup of patients endorsing LBP in the last 12 months. This enabled the additional items answered by these patients to be taken into account. The associations were reported as odds ratios. Multicollinearity of the predictor variables was assessed using Pearson correlation matrix. Predictors with a correlation $>0.4$ were excluded. The data was structured in a clustered format reflecting the nesting of patients within the 13 practices. Because patient views and expectations regarding back pain may be influenced by the doctor they consult, the responses of patients within the same cluster (medical practice) may thus have been correlated to one another [26]. Intraclass correlation coefficients (ICCs) were used to quantify the proportion of variation in the outcomes attributed to the cluster effect and thus evaluate the independence of individual data. The ICCs of the outcomes ranged from 0 to 0.05 , indicating a very low dependence of patient answers on the medical practice they visited. A sensitivity analysis using multivariate generalised logistic mixed regression models was performed. No meaningful differences in the results were found. As a result, the clusters were ultimately not considered in the analysis. Instead, logistic regression models were performed. The discrimination ability was assessed by the areas under the receiver operating characteristic (ROC) curve. Data analysis was planned a priori to assess differences in response according to age, gender, current or recent LBP and other demographic variables and performed using SAS Institute Inc., Cary, NC, USA, Software 9.4 .

\section{Results}

\section{Physician characteristics}

Data were obtained from 13 general practices. Of these, 12 were single practices and one was a group practice. Of the 13 participating GPs, $9(70 \%)$ were women and the mean age was 50 years (range $=38-63$ years). Nine of them saw 1000-1500 patients in a three-month interval, two saw 750-999 and two saw fewer than 750. The GPs had been practicing for a median of 12 years $\left(Q_{1}=3\right.$; $\left.\mathrm{Q}_{3}=16\right)$ at the time of study participation.

\section{Participant characteristics}

A total of 977 participants were included in the analysis (median age 57, $\mathrm{Q}_{1}: 40 ; \mathrm{Q}_{3}: 67,39 \%$ male, Table 2, Fig. 1). The number of patients participating from each practice ranged from 31 to 96 . More than $70 \%$ of the participants reported a good-to-excellent health status. Current LBP was reported by $21 \%$ of participants and $55 \%$ reported LBP in the last year. Approximately 5\% had a history of back surgery and $44 \%$ had received injection therapy for LBP in the past (Table 2).

Of the participants with LBP currently or during the last 12 months (76\%), 36\% were male, median age was $56\left(\mathrm{Q}_{1}: 41, \mathrm{Q}_{3}: 66\right), 75 \%$ had an educational level of $\leq 10$ years of school, $13 \%$ were consulting their GP for current 
Table 2 Demographics and low back pain characteristics of study participants

\begin{tabular}{|c|c|c|}
\hline Characteristic & $\begin{array}{l}\text { All } \\
\text { participants }\end{array}$ & $\begin{array}{l}\text { Participants with current low back } \\
\text { pain }\end{array}$ \\
\hline Age (median, $\left.\mathrm{Q}_{1} ; \mathrm{Q}_{3}\right)^{\mathrm{a}}$ & $57(40 ; 67)^{a}$ & $58(48 ; 68)^{d}$ \\
\hline Male (n, \%) & $381 / 974(39.1)$ & $76 / 211(36)$ \\
\hline \multicolumn{3}{|l|}{ Education (n, \%) } \\
\hline$<10$ years of school & 198/961 (20.6) & $55 / 207(26.6)$ \\
\hline 10 years of school & $519 / 961(54.0)$ & 110/207 (53.1) \\
\hline$>10$ years of school & 244/961 (25.4) & $42 / 207(20.3)$ \\
\hline \multicolumn{3}{|l|}{ Self-assessed health status, $n(\%)^{b}$} \\
\hline Excellent & 23/954 (3.3) & $1 / 208(0.3)$ \\
\hline Very good & $126 / 954(17.2)$ & $13 / 208(9.3)$ \\
\hline Good & $527 / 954(54.6)$ & $85 / 208(44.8)$ \\
\hline Fair & $234 / 954(21.0)$ & $86 / 208(35.6)$ \\
\hline Poor & $44 / 954(4.0)$ & $23 / 208(10.0)$ \\
\hline \multicolumn{3}{|l|}{ Low back pain $(n, \%)^{b}$} \\
\hline Currently experiencing low back pain & $211 / 960(20.6)$ & - \\
\hline Low back pain in the last 12 months & $501 / 960(54.8)$ & - \\
\hline Low back pain not in the last 12 months & $248 / 960(24.6)$ & - \\
\hline \multicolumn{3}{|l|}{ Only participants with current low back pain or during the last 12 months $(n=712)$} \\
\hline Presenting at the GP for low back pain $(n, \%){ }^{b}$ & $96 / 690(12.5)$ & $71 / 203(33.8)$ \\
\hline \multicolumn{3}{|l|}{ Low back pain on a 10-point scale in the last 12 months ${ }^{b}$} \\
\hline Median $\left(\mathrm{Q}_{1} ; \mathrm{Q}_{3}\right)$ & $5.0(3 ; 6)^{e}$ & $5.0(4 ; 7)^{f}$ \\
\hline - Mild (0-5) & $439 / 687(64.7)$ & $103 / 203(54.5)$ \\
\hline - Moderate $(6,7)$ & 162/687 (22.9) & $56 / 203(26.1)$ \\
\hline • Severe (8-10) & $86 / 687(12.4)$ & $44 / 203(19.5)$ \\
\hline Analgesics for low back pain in the last 12 months $(n, \%)$ b & $406 / 712(56.7)$ & 157/211 (73.9) \\
\hline $\begin{array}{l}\text { Interference of daily activity on a 10-point scale in the last } 12 \text { months (median, } \mathrm{Q}_{1} \text {; } \\
\mathrm{Q}_{3} \text { ) }\end{array}$ & $4.0(3 ; 6)^{c}$ & $5.0(3 ; 7)^{\mathrm{g}}$ \\
\hline Imaging for low back pain in the last 12 months $(n, \%)$ b & 194/705 (25.1) & 88/207 (39.6) \\
\hline Surgery for LBP $(n, \%)^{b}$ & $61 / 968(4.7)$ & $25 / 210(9.6)$ \\
\hline Injection therapy $(\mathrm{n}, \%)$ b & $472 / 961$ (43.9) & $148 / 2010(65.9)$ \\
\hline
\end{tabular}

${ }^{a}$ missing $=4,{ }^{b}$ weighted percentage, ${ }^{c}$ missing $=42,{ }^{d}$ missing $=2,{ }^{e}$ missing $=25,{ }^{f}$ missing $=8,{ }^{g}$ missing $=7$

$Q_{1}$ First quartile, $Q_{3}$ Third quartile

LBP at the time of study participation, $25 \%$ had imaging in the last year ( $\mathrm{x}$-ray, magnetic resonance imaging, or computer tomography) and 57\% had taken analgesics for LBP in the last 12 months. This subgroup reported a median LBP intensity of $5\left(\mathrm{Q}_{1}: 3, \mathrm{Q}_{3}: 6\right)$ and a median impairment of daily activity of $4\left(\mathrm{Q}_{1}: 3, \mathrm{Q}_{3}: 6\right)$ on a 10-point scale. Of those reporting severe pain intensity $88 \%$ took analgesics in the last 12 months. $72 \%$ with moderate and $45 \%$ with mild pain intensity took analgesics in the last 12 months.

\section{Expectations and beliefs}

\section{Descriptive statistics}

More than $65 \%$ of respondents indicated that they would agree or strongly agree to refrain from further examinations if their LBP was judged by the doctor to be of no serious concern (due to absence of red flags; addressed in Statement 3-1, G-LBP) (Table 3). About 40\% expected imaging in the workup for acute LBP (Statement 3-6, GLBP), 70\% expected a prescription for massages (Statement 5-17, G-LBP), 45\% injection therapy (Statement 6-27, G-LBP) and 64\% a referral for physiotherapy (Statement 5-6, G-LBP). About 66\% agreed that continuing everyday activities as much as possible was beneficial in managing back pain (recommendation 4-5 G-LBP) and $11 \%$ believed that there is no effective treatment for LBP.

\section{Multivariate analysis}

Refraining from further examinations The highest educational level (>10 years, OR: $2.10,95 \% \mathrm{CI}$ : 1.75 , 
Table 3 Patient agreement with core guideline recommendations for management of low back pain, weighted percentages $(n=$ 977)

\begin{tabular}{|c|c|c|c|c|c|}
\hline $\begin{array}{l}\text { Adaptation of statement based on core recommendations from the national guideline } \\
\text { for patients }\end{array}$ & $\begin{array}{l}\text { Strongly } \\
\text { agree }\end{array}$ & Agree & Disagree & $\begin{array}{l}\text { Strongly } \\
\text { disagree }\end{array}$ & $\begin{array}{l}\text { Do not } \\
\text { know }\end{array}$ \\
\hline $\begin{array}{l}\text { If I have low back pain that is judged to be of no serious concern after medical examination, I } \\
\text { am willing to refrain from further examination }(n, \%)^{a}\end{array}$ & $333(36.3)$ & $\begin{array}{l}278 \\
(30.7)\end{array}$ & $\begin{array}{l}118 \\
(12.5)\end{array}$ & $55(4.9)$ & $\begin{array}{l}172 \\
(13.9)\end{array}$ \\
\hline $\begin{array}{l}\text { If I have acute low back pain, without weakness or loss of sensation (prickle, numbness) in one } \\
\text { leg, I expect imaging ( } x \text {-ray, } C T, M R I)(n, \%)^{b}\end{array}$ & $181(18.0)$ & $\begin{array}{l}220 \\
(22.2)\end{array}$ & $\begin{array}{l}231 \\
(26.1)\end{array}$ & $171(18.4)$ & $\begin{array}{l}159 \\
(14.0)\end{array}$ \\
\hline If I have low back pain, I expect a prescription for massages $(n, \%)^{c}$ & $267(25.6)$ & $\begin{array}{l}394 \\
(44.2)\end{array}$ & $\begin{array}{l}139 \\
(14.2)\end{array}$ & $75(7.6)$ & $89(7.5)$ \\
\hline If I have low back pain, I expect injection therapy $(n, \%){ }^{d}$ & $146(13.2)$ & $\begin{array}{l}300 \\
(31.3)\end{array}$ & $\begin{array}{l}265 \\
(29.4)\end{array}$ & $130(14.1)$ & $\begin{array}{l}121 \\
(10.5)\end{array}$ \\
\hline $\begin{array}{l}\text { If I have acute low back pain (less than } 6 \text { weeks in duration), I expect a referral for } \\
\text { physiotherapy }(n, \%) \text { e }\end{array}$ & $255(25.4)$ & $\begin{array}{l}345 \\
(38.1)\end{array}$ & $\begin{array}{l}146 \\
(16.3)\end{array}$ & $103(9.7)$ & $113(9.5)$ \\
\hline If I have low back pain, I should continue my everyday activities as much as possible $(n, \%)^{f}$ & $227(22.4)$ & $\begin{array}{l}409 \\
(43.7)\end{array}$ & $\begin{array}{l}147 \\
(16.4)\end{array}$ & $72(7.2)$ & $108(9.3)$ \\
\hline There is no effective treatment for low back pain $(n, \%)^{g}$ & $39(3.2)$ & $\begin{array}{l}87 \\
(8.2)\end{array}$ & $\begin{array}{l}231 \\
(25.2)\end{array}$ & $273(30.6)$ & $\begin{array}{l}325 \\
(31.1)\end{array}$ \\
\hline
\end{tabular}

${ }^{\mathrm{a}}$ missing $=21(1.7 \%),{ }^{\mathrm{b}}$ missing $=15(1.4 \%),{ }^{\mathrm{c}}$ missing $=13(1.0 \%),{ }^{\mathrm{d}}$ missing $=15(1.6 \%),{ }^{\mathrm{e}}$ missing $=15(1.1),{ }^{\mathrm{f}}$ missing $=14(1.4 \%),{ }^{\mathrm{g}} \mathrm{missing}=22(1.7 \%)$

2.53) and LBP in the last 12 months were associated with the expectation that no further examinations should take place (Table 4). Compared to those with very good or excellent health status, participants of good or poor health status were less likely to agree to forego further examinations for the workup of LBP. In the subgroup of participants with LBP in the last 12 months, participants with no prior imaging (OR: 2.41, 95\% CI: 2.08, 2.79) agreed to refrain from further examinations, while participants with a moderate or severe pain intensity, a poor health status and participants who took analgesics did not agree to refrain from further examinations if their pain was judged to be of no serious concern by their physician (Table 5).

Imaging The highest level of education ( $>10$ years) and female gender were associated with a decreased expectation of imaging, while a good (OR: 1.35, 95\% CI: 1.19, 1.52 ) or -poor (OR: $2.36,95 \%$ CI: $2.04,2.74$ ) health status and LBP in the last 12 months were associated with an increased expectation of imaging (Table 4). Additionally, in this subgroup, a lack of prior imaging was associated with a decreased expectation of imaging in the workup of LBP (Table 5).

Massages Female participants, participants with goodto-poor health status, and participants with current LBP or LBP in the last 12 months were more likely to expect a prescription for massages (Table 4). In the subgroup analysis, participants with a good-to-poor health status were more likely to expect a prescription for massages. Participants who took analgesics for LBP in the last 12 months did not expect massages (Table 5).
Injection therapy Female participants, participants with a higher educational level (10 years and $>10$ years of school) with a good-to-poor health status, and participants with current LBP or LBP in the last 12 months were less likely to expect injection therapy. Participants who had previously received injection therapy in the treatment of LBP had a high expectation of injection therapy (OR: 2.14, 95\% CI: 1.94, 2.35) (Table 4). Participants with moderate LBP intensity and participants who took analgesics in the last 12 months were more likely to expect injection therapy (Table 5).

Physiotherapy Female participants, participants with 10 years of education, with good or poor health status, and participants with current LBP or LBP in the last 12 months expected a referral for physiotherapy (Table 4). In participants with LBP in the last 12 months, only the female gender and a good or poor health status and analgesics in the last 12 months were associated with the expectation of physiotherapy (Table 5).

Continuing everyday activities Female participants (OR: 2.47, 95\% CI: 2.22, 2.76), participants with a higher educational level (10 years and $>10$ years), and participants with current LBP (OR: $2.36,95 \%$ CI: 1.99, 2.80) or LBP in the last 12 months indicated agreement regarding the benefits of continuing everyday activity despite LBP. Participants with good or poor health status (Table 4) and those with severe pain intensity during the last 12 months were more likely to disagree that they should continue everyday activity while experiencing LBP (Table 5). Participants who took analgesics were more likely to agree (Table 5). 


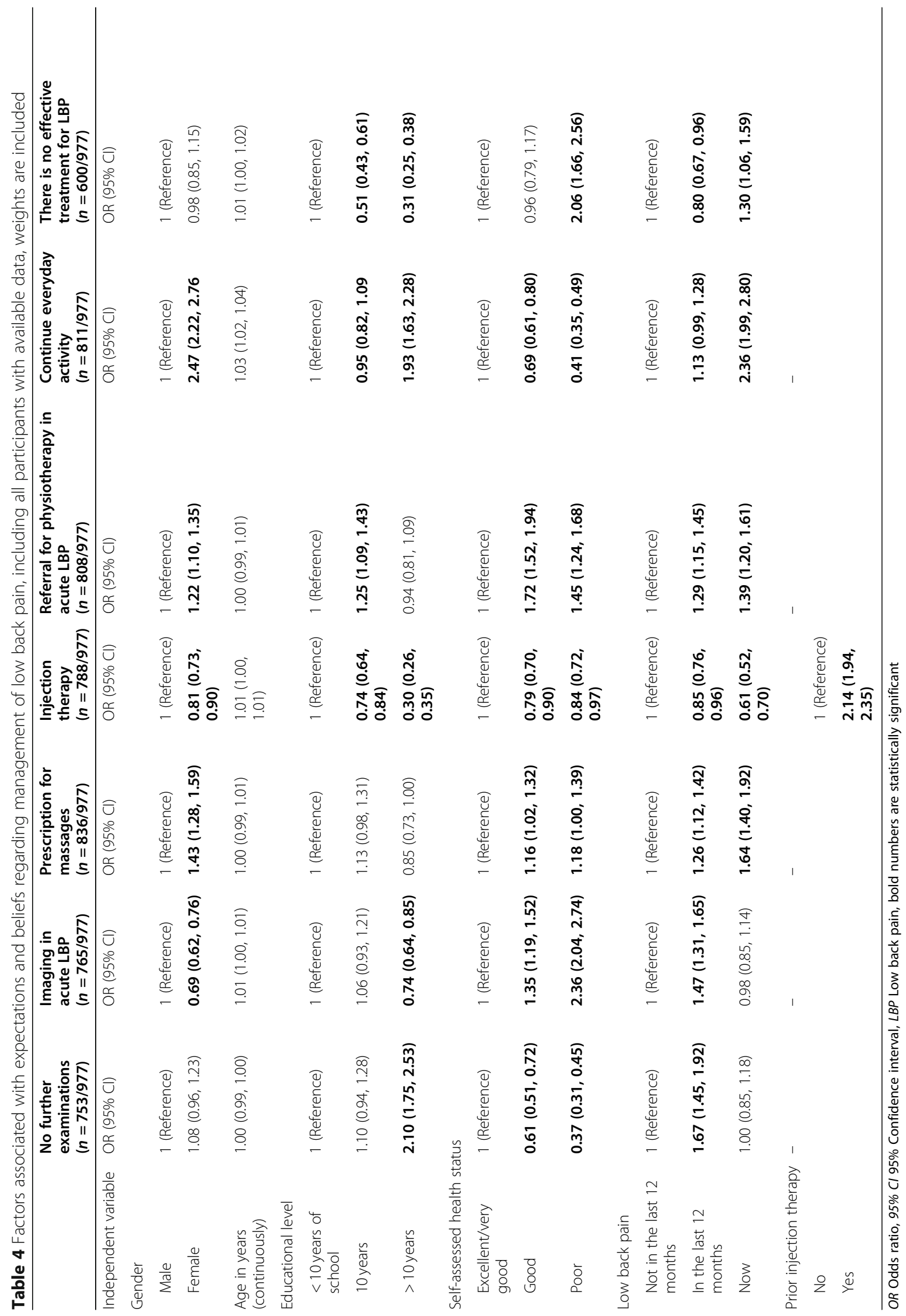




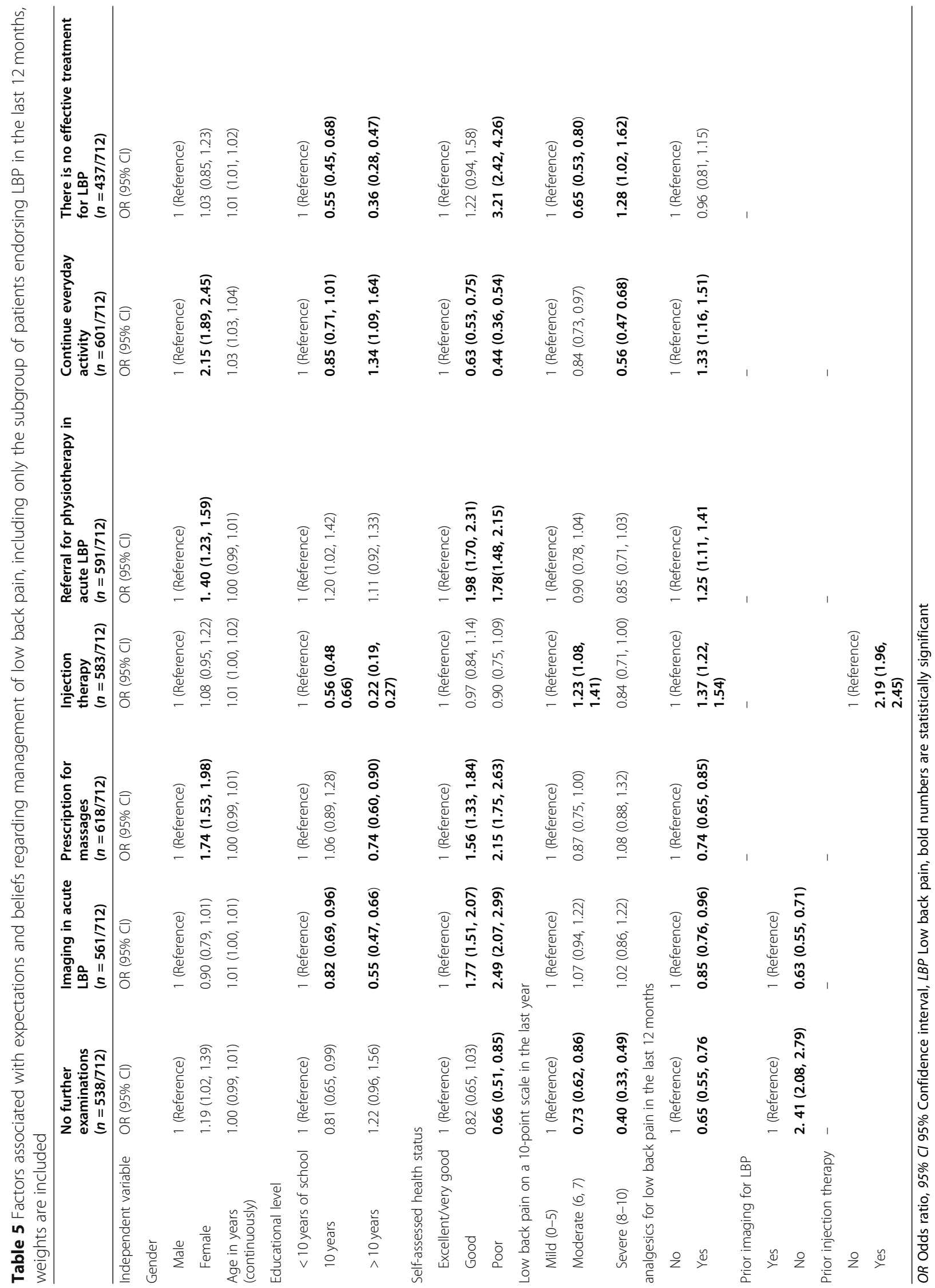


Belief in effective treatment Participants with a higher educational level (10 and $>10$ years) and participants with LBP in the last 12 months were less likely to agree that there is no effective treatment for LBP. Participants with poor health status (OR: 2.06, 95\% CI: 1.66, 2.56) and participants with current LBP were more likely to agree that there is no effective treatment (Table 4). Participants experiencing moderate-intensity LBP were less likely to believe that there is no effective treatment for LBP while participants with severe LBP were more likely to believe there is no effective treatment (Table 5).

\section{Discussion}

\section{Summary of main results}

More than half of participants (67\%) indicated that they would agree to refrain from further examinations if their LBP was judged by their doctor to be of no serious concern (absence of red flags). About $40 \%$ expected imaging workup, $70 \%$ a prescription for massages, $45 \%$ injection therapy, and $64 \%$ a referral for physiotherapy. About $66 \%$ agreed to continue everyday activity despite LBP and $11 \%$ believed there is no effective treatment for LBP. These expectations and beliefs were dependent on gender, educational level, self-assed health status, current LBP and LBP in the last 12 months, pain intensity, use of analgesics, prior imaging and prior injection therapy.

\section{Interpretation of results}

\section{Suffering from and seeking care for LBP}

Our study findings correspond to the one-year LBP prevalence of $76 \%$ in the German adult population reported in another study [27]. The majority of patients with a history of LBP in the last 12 months were female. Gender imbalances in LBP are also shown in other studies [28-30]. However, in our study the majority of people suffering from LBP were not actively seeking medical care at the time of participation. Only 13\% of participants with current LBP or LBP during the last 12 months listed LBP as the reason for GP consultation on the questionnaire. When considering only participants with current LBP the percentage increased to $34 \%$. It is possible that these participants had already sought care for their LBP or were planning to in the future. In Germany, roughly $25 \%$ of the population annually seek medical care for LBP [3]. The majority of participants suffering from LBP during the last 12 months had a lower educational level ( $\leq 10$ years). This result is concordant with a German study [31], where $83 \%$ of participants with lower educational levels suffered from LBP compared to $62 \%$ of those with university degrees.

\section{Refraining from further examinations}

The agreement from $67 \%$ of participants to refrain from further examinations in the absence of "red flags" is in accordance with national and international guidelines for the management of LBP. Of note, participants who indicated agreement to forego further testing had no prior imaging for LBP. Participants suffering from moderate-to-severe LBP currently or within the last 12 months did not agree to refrain from further examinations. Similar results were found in a qualitative Australian study, where patients with severe pain were more likely to expect $\mathrm{x}$-rays and prior experiences of care had an influence on current expectations regarding LBP management [32]. Also, participants who took analgesics in the last 12 months did not agree to refrain from further examinations. These results are in line with the pain intensity. Although, not all participants with severe pain took analgesics in the last 12 months. Expectations for imaging. A report including more than 5 million German patients covered by statutory health insurance with the billing diagnosis of back pain found that 375 of 1000 patients had imaging workup during 1 year [33]. The imaging rate in our study population was lower (275 per 1000) but still suggests overuse given that imaging is only recommended with high suspicion for specific LBP (Statement 3-6, G-LBP). The high frequency of imaging in LBP patients and the lack of clinical benefit is a wellknown phenomenon [33-35]. A systematic review and meta-analysis concluded that abnormalities identified by MRI are very common even in asymptomatic individuals and do not coincide with LBP development [36]. Imaging workup in patients with non-specific LBP has also been shown to be of no clinical benefit for the patient $[14,37]$. Moreover, imaging workup in LBP can lead to increased surgery rates [14, 33, 37]. In our study, $40 \%$ of patients believed imaging was necessary in the workup and treatment of LBP. In the entire study population, the highest educational level (>10 years of school) and female gender were associated with a decreased expectation for imaging. In patients with LBP currently or within the last year, a lack of prior imaging was associated with a decreased expectation of imaging. A patient survey from Jenkins et al. [24] found a similar rate (48\%) of patients expecting imaging, with the same associations. The association between previous imaging and the strong belief in the need for imaging seems to be the basis for a cycle of health care use in LBP [24]. It is unknown if this patient belief is influenced by the treating clinicians [24]. A systematic review of interventions to reduce imaging in LBP showed inconsistent effects [35]. To our knowledge, there exist no studies assessing the best way for physicians to communicate the limited benefit of imaging in LBP to patients.

\section{Expectations for injection therapy}

The G-LBP firmly recommends against the injection of non-steroidal anti-inflammatory drugs (NSAIDs). 
Injections are not superior to oral applications and have additional injection-related risks of complications such as infection or physical injury [5, 38]. However, GPs assume that patients insist on injection therapy because they believe intramuscular injections lead to a faster and better pain relieve compared to oral application [38]. A large proportion $(45 \%)$ of participants in our study expected injection therapy in the treatment of LBP. These participants often had previously received injection therapy for LBP (OR: > 2) and took analgesics for LBP during the last 12 months. The previous experience of analgesics and injection therapy may imply a similar cycle of reinforcement as seen with previous imaging. Increasing patient education and awareness may help to interrupt this cycle. It has been shown that providing patients with information about the risks of oral versus injected NSAID influences patients decisions regarding mode of administration [38]. According to our findings, patients with LBP and no previous injection therapy do not expect injection therapy.

\section{Massages and physiotherapy}

The G-LBP does not recommend massages for LBP and physiotherapy is only recommended for subacute (lasting 4-12 weeks) and chronic (lasting $>12$ weeks) LBP due to insufficient evidence of effective treatment $[4,5]$. Yet, most patients (70\%) expected massages and $63 \%$ expected physiotherapy. This expectation was mainly associated with female gender and a good-to-poor health status. Participants with current LBP had an increased expectation of massages and referral to physiotherapy.

\section{Continuing everyday activities}

Two-thirds (66\%) of patients agreed to continue their everyday activities despite LBP. In a cohort study from Werber et al. [31], only $38 \%$ considered maintaining physical activities as helpful while experiencing LBP. We observed that a higher educational level ( $\geq 10$ years) and female gender were associated with the belief that everyday activity should be continued, while participants with a good-to-poor health status disagreed. Overall, patients with current LBP were more likely to agree that everyday activities should be continued, potentially reflecting recent physician recommendations to continue daily activities. However, of patients with current or recent LBP, those with severe pain disagreed that everyday activity should be continued. This finding is in accordance with the literature, which shows that patients reporting higher levels of disability more strongly believed they should avoid physical activity (also known as fear of pain due to movement or kinesiophobia) [22, 39, 40].

\section{Belief in effective treatment}

Participants with a higher educational level ( $\geq 10$ years) and LBP in the last year were less likely to believe there is no effective treatment for LBP while participants with a poor health status, current LBP, and severe pain intensity believed there is no effective treatment. Werber et al. also found significant differences in educational levels of patients endorsing varying perspectives on LBP management [31].

\section{Strategies to influence patient expectations}

The influence of public campaigns to change patient beliefs about back pain was investigated in four large studies (in Australia, Norway, Canada, and Scotland). The public health campaign in Australia was successful in altering general population beliefs and beliefs about back pain [41]. The mass media campaigns in Canada and Norway only had a small impact on altering back pain beliefs $[42,43]$ and the campaign in Scotland lead to a major shift in public beliefs but exerted no impact on work-related outcomes [44]. It was discussed that the small impact of the Canadian and Norwegian campaign may be due to the relatively small target area, low budget, and failure to directly address work-related issues [42-44]. Policymakers and third-party payers assessing guideline adherence using quality indicators should consider the difficult position of clinicians as they seek to balance patient expectations and preferences with potentially conflicting guideline recommendations.

We found that prior treatment experience exerted a strong influence on patient expectations $(\mathrm{OR}>2)$ compared to other factors with mostly small influences on expectations. As a result, a feasible strategy to align LBP treatment in practice with guidelines could be to avoid initiation of non-recommended therapies in patients seeking care for LBP for the first time. This can potentially change patient expectations of future management of LBP and decrease pressure on physicians.

\section{Strengths and limitations}

Considerable strengths of this study are the large sample and the high response rate of $87 \%$. Inverse probability weights were used to account for the nonresponse bias [45]. Furthermore, the results remained robust in a sensitivity analysis considering the clustered structure, confirming the independence of individual data. Our questionnaire was tailored to the G-LBP; however, for this reason we could not use a validated instrument. Our questionnaire was piloted in three general practices with 139 patients. Additionally, cognitive interviewing was used on a subsample as a method of validity evidence [46]. Patients completed the questionnaire before seeing their GP, a measure meant to minimize potential GPinfluence on patient answers. In addition, patients were 
asked to recall their history of LBP, which could have caused a recall bias. However, the influence from a recall bias may be low, because we limited the recall time to the last 12 months. We did not collect data on income, working status and specific co-morbidities, which might have affected responses. However, these factors are partially reflected by educational status, health status, and being of working age. We may underestimate patient disagreement with guideline recommendations due to social desirability bias [47]. Patient expectations are shaped by the health care system, e.g. access to care or co-payments; this should be kept in mind when generalizing our data.

\section{Conclusion}

Our study indicates that patient views regarding management of LBP in an ambulatory care setting are only partially concordant with guideline recommendations for LBP. Patient beliefs and expectations regarding LBP management are strongly influenced by previous treatment experiences, educational level, and, in some cases, gender. Given the potential impact on patient satisfaction, further exploration of previous treatments experienced by patients and their current expectations may help increase physician guideline adherence and minimize the dissatisfaction of patients who expect treatments not endorsed by guidelines.

\section{Supplementary Information}

The online version contains supplementary material available at https:/doi. org/10.1186/s12875-020-01352-1.

\section{Additional file 1}

\section{Abbreviations \\ G-LBP: Guideline for management of low back pain; GP: General Practitioner; ICC: Intraclass correlation coefficient; ipw: Inverse probability weight; LBP: Low back pain; NSAIDS: Nonsteroidal anti-inflammatory drugs; $Q_{1}$ : First} quartile; $\mathrm{Q}_{3}$ : Third quartile; YLD: Years lived with disability

\section{Acknowledgements}

We are grateful to the general practices and all people participating in the study.

\section{Authors' contributions}

The design and conception of the study was performed by CR, J-F C and PK. Data collection was performed by CR and PK. SK was a major contributor in data analysis and together with ES in writing the manuscript. All authors read and approved the final version of the manuscript.

\section{Funding}

This study was not funded. Open Access funding enabled and organized by Projekt DEAL.

\section{Availability of data and materials}

The dataset used and analysed during the current study are available from the corresponding author on reasonable request.

\section{Ethics approval and consent to participate}

The ethical review board of the University Medicine Greifswald gave ethics approval for this study (approval no.: BB148/16). All patients provided written informed consent before participation.

\section{Consent for publication}

Not applicable.

\section{Competing interests}

Jean-François Chenot is one of the lead authors of the German national disease management guideline for low back pain. He is also an editorial board member of BMC Family Practice.

\section{Author details}

'Department of General Practice, Institute of Community Medicine, University Medicine Greifswald, Fleischmannstraße 6, 17475 Greifswald, Germany.

${ }^{2}$ General Practice, Peggy Knauthe, Reinberg, Germany.

Received: 18 June 2020 Accepted: 10 December 2020

Published online: 21 December 2020

\section{References}

1. James SL, Abate D, Abate KH, Abay SM, Abbafati C, Abbasi N, et al. Global, regional, and national incidence, prevalence, and years lived with disability for 354 diseases and injuries for 195 countries and territories, 1990-2017: a systematic analysis for the global burden of disease study 2017. Lancet. 2018;392(10159):1789-858.

2. Neuhauser $\mathrm{H}$, Ellert U, Ziese T. Chronische Rückenschmerzen in der Allgemeinbevölkerung in Deutschland 2002/2003: Prävalenz und besonders betroffene Bevölkerungsgruppen [Chronic Back Pain in the General Population in Germany 2002/2003:Prevalence and Highly Affected Population Groups]. Gesundheitswesen. 2005;67(10):685-93.

3. Chenot JF, Haupt C, Gerste B. Zeitliche Trends bei der Versorgung von Rückenschmerzpatienten [Trends in care of back pain patients]. In: Klauber J, Günster C, Gerste B, Robra B-P, Schmacke N, editors. Versorgungs-report 2013: Schwerpunkt: depression - Mit online-Zugang zum internet-portal: www.versorgungs-report-online.de.1.Aufl. Stuttgart: Schattauer; 2013. p. $155-84$

4. Oliveira CB, Maher CG, Pinto RZ, Traeger AC, Lin C-WC, Chenot J-F, et al. Clinical practice guidelines for the management of non-specific low back pain in primary care: an updated overview. Eur Spine J. 2018;27(11):2791803.

5. Nationale VersorgungsLeitlinie Nicht-spezifischer Kreuzschmerz [Clinical practice guideline: Non-specific low back pain]: Langfassung; 2017 [cited 2019 Jul 1]. Available from: URL: https://www.leitlinien.de/mdb/downloads/ nvl/kreuzschmerz/kreuzschmerz-2aufl-vers1-lang.pdf.

6. Maher C, Underwood M, Buchbinder R. Non-specific low back pain. Lancet. 2017:389(10070):736-47.

7. Williams CM, Maher CG, Hancock MJ, McAuley JH, McLachlan AJ, Britt H, et al. Low back pain and best practice care: a survey of general practice physicians. Arch Intern Med. 2010;170(3):271-7.

8. González-Urzelai V, Palacio-Elua L, López-de-Munain J. Routine primary care management of acute low back pain: adherence to clinical guidelines. Eur Spine J. 2003;12(6):589-94

9. Piccoliori G, Engl A, Gatterer D, Sessa E, Schmitten J. In der, Abholz H-H. management of low back pain in general practice - is it of acceptable quality: an observational study among 25 general practices in South Tyrol (Italy). BMC Fam Pract. 2013;14:148.

10. Feuerstein M, Hartzell M, Rogers HL, Marcus SC. Evidence-based practice for acute low back pain in primary care: patient outcomes and cost of care. Pain. 2006;124(1-2):140-9.

11. Slade SC, Kent P, Patel S, Bucknall T, Buchbinder R. Barriers to primary care clinician adherence to clinical guidelines for the Management of low Back Pain: a systematic review and Metasynthesis of qualitative studies. Clin J Pain. 2016;32(9):800-16.

12. Dey P, Simpson CWR, Collins SI, Hodgson G, Dowrick CF, Simison AJM, et al. Implementation of RCGP guidelines for acute low back pain: a cluster randomised controlled trial. $\mathrm{Br} J$ Gen Pract 2004;54(498):33-7.

13. Schectman JM, Schroth WS, Verme D, Voss JD. Randomized controlled trial of education and feedback for implementation of guidelines for acute low Back pain. J Gen Intern Med. 2003;18(10):773-80. 
14. Reed SJ PS. Choosing Wisely Recommendation Analysis: Prioritizing Opportunities for Reducing Inappropriate Care: Imaging for nonspecific low back pain: Institute for Clinical and Economic Review; 2015 [cited 2019 Jul 30]. Available from: URL: https://collections.n/m.nih.gov/master/borndig/1 01654291/Choosing\%20Wisely\%20Recommendation\%20Analysislmagingfor-Low-Back-Pain.pdf.

15. Chenot J-F, Scherer M, Becker A, Donner-Banzhoff N, Baum E, Leonhardt C, et al. Acceptance and perceived barriers of implementing a guideline for managing low back in general practice. Implement Sci. 2008;3:7.

16. Schers $H$, Braspenning J, Drijver R, Wensing M, Grol R. Low back pain in general practice: reported management and reasons for not adhering to the guidelines in the Netherlands. Br J Gen Pract. 2000;50(457):640-4.

17. Eisenberg DM, Post DE, Davis RB, Connelly MT, Legedza ATR, Hrbek AL, et al. Addition of choice of complementary therapies to usual care for acute low back pain: a randomized controlled trial. Spine. 2007;32(2):151-8.

18. George SZ, Robinson ME. Preference, expectation, and satisfaction in a clinical trial of behavioral interventions for acute and sub-acute low back pain. J Pain. 2010;11(11):1074-82.

19. Bishop MD, Mintken PE, Bialosky JE, Cleland JA. Patient expectations of benefit from interventions for neck pain and resulting influence on outcomes. J Orthop Sports Phys Ther. 2013;43(7):457-65.

20. Dionne CE, Bourbonnais R, Frémont P, Rossignol M, Stock SR, Nouwen A, et al. Determinants of "return to work in good health" among workers with back pain who consult in primary care settings: a 2-year prospective study. Eur Spine J. 2007;16(5):641-55.

21. Lim YZ, Chou L, Au RT, Seneviwickrama KMD, Cicuttini FM, Briggs AM, et al. People with low back pain want clear, consistent and personalised information on prognosis, treatment options and self-management strategies: a systematic review. J Physiother. 2019;65(3):124-35.

22. Main CJ, Foster N, Buchbinder R. How important are back pain beliefs and expectations for satisfactory recovery from back pain? Best Pract Res Clin Rheumatol. 2010;24(2):205-17.

23. Chenot J-F, Greitemann B, Kladny B, Petzke F, Pfingsten M, Schorr SG. Nonspecific low Back pain. Dtsch Arztebl Int. 2017;114(51-52):883-90.

24. Jenkins HJ, Hancock MJ, Maher CG, French SD, Magnussen JS. Understanding patient beliefs regarding the use of imaging in the management of low back pain. Eur J Pain. 2016;20(4):573-80.

25. Boonstra AM, Stewart RE, Köke AJA, Oosterwijk RFA, Swaan JL, Schreurs KMG, et al. Cut-off points for mild, moderate, and severe pain on the numeric rating scale for pain in patients with chronic musculoskeletal pain: variability and influence of sex and Catastrophizing. Front Psychol. 2016;7: 1466.

26. Austin PC, Merlo J. Intermediate and advanced topics in multilevel logistic regression analysis. Stat Med. 2017;36(20):3257-77.

27. Schmidt CO, Raspe H, Pfingsten M, Hasenbring M, Basler HD, Eich W, et al. Back pain in the German adult population: prevalence, severity, and sociodemographic correlates in a multiregional survey. Spine. 2007;32(18): 2005-11.

28. Schneider S, Randoll D, Buchner M. Why do women have back pain more than men? A representative prevalence study in the federal republic of Germany. Clin J Pain. 2006;22(8):738-47.

29. Strowbridge NF. Gender differences in the cause of low back pain in British soldiers. J R Army Med Corps. 2005;151(2):69-72.

30. Raspe H-H. Rückenschmerzen [Back pain]. Berlin: Robert-Koch-Inst; 2012. (Gesundheitsberichterstattung des Bundes; vol 53).

31. Werber A, Zimmermann-Stenzel M, Moradi B, Neubauer E, Schiltenwolf M. Awareness of the German population of common available guidelines of how to cope with lower back pain. Pain Physician. 2014;17(3):217-26.

32. Hoffmann TC, Del Mar CB, Strong J, Mai J. Patients' expectations of acute low back pain management: implications for evidence uptake. BMC Fam Pract. 2013;14:7

33. Andersohn F. WJ. Faktencheck Rücken [facts on back pain]: Ausmaß und regionale Variationen von Behandlungsfällen und bildgebender Diagnostik: ingef und BertelsmannStiftung; 2016 [cited 2019 Jul 1]. Available from: URL: https://www.bertelsmann-stiftung.de/fileadmin/files/BSt/Publikationen/ GrauePublikationen/Studie_W_FC_Ruecken_Behandlungsfaelle-Bildgebung. pdf.

34. Balagué F, Mannion AF, Pellisé F, Cedraschi C. Non-specific low back pain. Lancet. 2012;379(9814):482-91.
35. Jenkins HJ, Hancock MJ, French SD, Maher CG, Engel RM, Magnussen JS. Effectiveness of interventions designed to reduce the use of imaging for low-back pain: a systematic review. CMAJ. 2015;187(6):401-8.

36. Endean A, Palmer KT, Coggon D. Potential of magnetic resonance imaging findings to refine case definition for mechanical low back pain in epidemiological studies: a systematic review. Spine. 2011;36(2):160-9.

37. Jarvik JG, Hollingworth W, Martin B, Emerson SS, Gray DT, Overman S, et al. Rapid magnetic resonance imaging vs radiographs for patients with low back pain: a randomized controlled trial. JAMA. 2003;289(21):2810-8.

38. Rosemann T, Joos S, Koerner T, Heiderhoff M, Laux G, Szecsenyi J. Use of a patient information leaflet to influence patient decisions regarding mode of administration of NSAID medications in case of acute low back pain. Eur Spine J. 2006;15(11):1737-41.

39. Turk DC, Wilson HD. Fear of pain as a prognostic factor in chronic pain: conceptual models, assessment, and treatment implications. Curr Pain Headache Rep. 2010;14(2):88-95.

40. Ibrahim ME, Weber K, Courvoisier DS, Genevay S. Big five personality traits and disabling chronic low Back pain: association with fear-avoidance, anxious and depressive moods. J Pain Res. 2020;13:745-54.

41. Buchbinder R, Jolley D, Wyatt M. Population based intervention to change back pain beliefs and disability: three part evaluation. BMJ. 2001;322(7301): 1516-20.

42. Gross DP, Russell AS, Ferrari R, Battié MC, Schopflocher D, Hu R, et al. Evaluation of a Canadian back pain mass media campaign. Spine. 2010; 35(8):906-13.

43. Werner EL, Ihlebaek C, Laerum E, Wormgoor MEA, Indahl A. Low back pain media campaign: no effect on sickness behaviour. Patient Educ Couns. 2008;71(2):198-203.

44. Waddell G, O'Connor M, Boorman S, Torsney B. Working backs Scotland: a public and professional health education campaign for back pain. Spine. 2007;32(19):2139-43.

45. Härkänen T, Kaikkonen R, Virtala E, Koskinen S. Inverse probability weighting and doubly robust methods in correcting the effects of non-response in the reimbursed medication and self-reported turnout estimates in the ATH survey. BMC Public Health. 2014;14:1150.

46. Pepper D, Hodgen J, Lamesoo K, Kõiv P, Tolboom J. Think aloud: using cognitive interviewing to validate the PISA assessment of student selfefficacy in mathematics. Int J Res Method Educ. 2018;41(1):3-16.

47. Deshields TL, Tait RC, Gfeller JD, Chibnall JT. Relationship between social desirability and self-report in chronic pain patients. Clin J Pain. 1995;11(3): 189-93.

\section{Publisher's Note}

Springer Nature remains neutral with regard to jurisdictional claims in published maps and institutional affiliations.

Ready to submit your research? Choose BMC and benefit from:

- fast, convenient online submission

- thorough peer review by experienced researchers in your field

- rapid publication on acceptance

- support for research data, including large and complex data types

- gold Open Access which fosters wider collaboration and increased citations

- maximum visibility for your research: over $100 \mathrm{M}$ website views per year

At BMC, research is always in progress.

Learn more biomedcentral.com/submissions 